\author{
Military Technical College \\ Kobry El-Kobbah, \\ Cairo, Egypt.
}

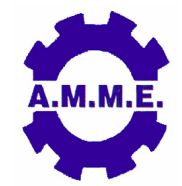

\title{
MODELING PENETRATION OF BI-ELEMENT METALLIC TARGETS BY HIGH-SPEED PROJECTILES
}

\author{
H. A. Abou-Elela*, A. M. Riad*, A. I. Fayed* and M. A. Shaker
}

\begin{abstract}
In this paper, an analytical model is proposed to describe the penetration of a high-speed projectile into a metallic bi-element target, consisting of a finite thickness metallic layer facing a semi-infinite RHA armor. The proposed model identifies two main phases for target penetration; these are: (i) penetration of the front metallic layer and (ii) penetration of backing semi-finite metallic armor. During the target penetration phases, three modes of the projectile front may occur; these are erosion, mushrooming and rigid modes [1, 6]. Main assumptions and governing equations of each target penetration phase for each mode of projectile front are presented. These equations are arranged and compiled into a computer program. The input data to the program are easily determined.
\end{abstract}

The measured penetration depths of depleted uranium (DU) projectiles into semiinfinite RHA armor at different impact velocities of Ref. [4, 5] are compared with the corresponding model predictions to determine the RHA flow stress. In addition, the model predictions are compared with the ballistic measurements of Ref. [4] to determine the flow stress of front metallic layer materials of the bi-element targets. The present model is also used to predict the ballistic efficiencies of the front titanium plates with different thicknesses when each of them is backed by a semi-infinite RHA armor. Moreover, predicted samples for the influence of the projectile impact velocity on the ballistic efficiency are presented and discussed.

\section{KEY WORDS}

Bi-element targets, titanium, penetration, erosion, bi-element metallic targets, semiinfinite targets, impact dynamics, penetration model.

\footnotetext{
* Egyptian Armed Forces.
} 


\section{NOMONCLATURE}

$A_{O}$

a, b

AD99.5

$C_{t}$

$\mathrm{C}_{\mathrm{a}}$

$\mathrm{C}_{\mathrm{xp}}$

$\mathrm{C}_{\mathrm{xt}}$

$D_{0}$

E

$E_{p}$

$E_{m}$

$E^{*} \mathrm{~m}$

$F$

$\mathrm{H}_{\mathrm{AO}}$

$\mathrm{H}_{\mathrm{A}}$

$\mathrm{H}_{\mathrm{A}}^{*}$

$L_{O}$

$L$

$L_{E R O}$

$L_{E L A S}$

$\mathrm{L} / \mathrm{D}$

SI

$t$

$t_{E R O}$

$t_{\text {mush }}$

$U$

$U_{O L D}$

DU $3 / 4 \% \mathrm{Ti}$

$U^{\prime}$

V

$V_{i}$

$V_{P L A S}$

$V_{\text {SONIC }}$

W

$W^{*}$

$Y_{B}$

$Y_{P}$

Initial cross section area of projectile.

Coefficients.

Alumina ceramic with $99.5 \%$ purity.

Flow stress multiplier of backing material.

Flow stress multiplier of titanium material.

Flow stress multiplier of projectile material.

Flow stress multiplier of target material.

Initial diameter of projectile.

Elastic modulus.

Elastic modulus of projectile material.

Ballistic efficiency.

Mass efficiency of limit thickness of front layer.

Interface force.

Thickness of front metallic plate.

Thickness of plate material after time $t$.

Limit titanium thickness, where no penetration occurs in back plate Initial length of projectile.

Length of projectile rigid mass after time $t$.

Remaining length of projectile at the end of erosion phase.

Projectile length which is not influenced by plastic wave.

Length to diameter (aspect) ratio of projectile.

Penetration into semi-infinite metallic backing phase.

Time of penetration.

Time at which erosion of projectile front is terminated.

Time of projectile mushrooming duration.

Penetration velocity at time $t$.

penetration velocity at the previous time increment,

Depleted uranium with $0.75 \%$ titanium content.

Projectile deceleration.

Velocity of rigid mass of projectile at time t.

Impact velocity.

Plastic wave velocity.

Sonic wave velocity inside material (elastic wave velocity) which is equal to $\sqrt{E / \rho}$.

Mass saving.

Limit mass saving for front plate armor thickness.

Flow stress of backing material.

Flow stress of projectile material. 

Z
Projectile penetration depth at time $t$.
$Z_{\mathrm{ex}}$
Measured total penetration depth.
$Z_{\text {pred }}$
Predicted total penetration depth.
$Z_{\text {res }}$
Residual penetration depth into back plate.
$Z_{s t}$
Depth of projectile penetration into reference steel target.
$\rho_{A}$
Density of metallic front layer material
$\rho_{B}$
Density of back plate material.
$\rho_{P}$
Density of projectile material.
$\rho_{s t}$
Density of reference steel.
$\sigma_{y p}^{D}$
Dynamic yield strength of projectile material.
$\sigma_{y t}^{D}$
Dynamic yield strength of backing target material.
$\mu_{A}$
The ratio of the density of titanium armor material to the density of projectile material.
$\mu_{B}$ The ratio of the density of semi-infinite armor material to the density of projectile material.

\title{
Abbreviation
}

\author{
BHN \\ Brinell Hardness Number. \\ DU \\ Depleted Uranium. \\ $\mathrm{RHA}$ \\ Rolled Homogenous Armor. \\ $\mathrm{Ti}$ \\ Titanium. \\ Ti-6Al-4V Titanium alloy with $6 \%$ aluminum and $4 \%$ vanadium content.
}

\section{INTRODUCTION}

$\mathrm{Bi}$ - element armor concept is one of the solutions to defeat long rod penetartors with enhanced penetration capabilities. The front layer material in bi-element armor must have high strength to density ratio and less weight compared with that of Rolled homogenous Armor (RHA). The task of the font layer is to break up the tip of the projectile, erodes the projectile and decelerates it in such way that no or less penetration may occur into the backing layer. The backing layer must have suitable density, high tensile strength, sufficient bulk and rigidity modulii to stop the remaining of the projectile [1]. It could be of finite thickness or semi-infinite thickness of metal or composite. Both thickness and material type of the bi-element targets depend mainly on the threat that needs to be defeated.

Ceramics are commonly used as front layers of the bi-element armors for their superior properties such as high hardness and low density. Another candidate for this position is titanium alloy which has lightweight, corrosion resistant, and high strength material. The density of titanium is about $60 \%$ of steel. Aluminum, magnesium, and beryllium are the only base metals and lighter than titanium; none 
of them come close to titanium in mechanical performance (except beryllium with respect to stiffness) [2]. Titanium alloys are known to have favorable properties for armor applications; e.g. Ti-6Al-4V. Now, low cost grades of this alloy are available and substantial work has been undertaken to characterize the ballistic performance of low-cost Ti-6Al-4V against modern threats [3].

Rupert and Grace [4] studied experimentally the impact of a Depleted Uranium (DU) long rod projectile with an aspect ratio of 10 and a diameter of $7.7 \mathrm{~mm}$ into two groups of different bi-element target configurations; the first group consisted of titanium plate with different thicknesses facing a semi-infinite RHA, whereas the second group consisted of RHA with different thicknesses facing a semi-infinite titanium armor. The projectile impact velocity was $1500 \mathrm{~m} / \mathrm{s}$. They found that the ballistic efficiencies of the first group of bi-element targets were more than the second group.

Burkins, et al. [5] performed a series of ballistic firing tests to study the ballistic performance of titanium alloy Ti-6A1-4V when used as semi-infinite backing into bi-element targets compared with RHA. The tests were performed by tungsten alloy and DU long rod projectiles used in Ref. [4]. The impact velocities were ranged from $1000 \mathrm{~m} / \mathrm{s}$ to $1900 \mathrm{~m} / \mathrm{s}$. The depth of penetration was measured for each test. They concluded that mass efficiency for Ti-6A1-4V is better compared with RHA.

Thorn and Cimpoeru [3] performed an experimental program to study the ballistic performance of two different grades of titanium alloy, Ti-6Al-4V and Ti-8Al-1Mo-1V, which were applied as appliqués to semi-infinite 5083 aluminum targets. Two target thicknesses and a bi-layer laminate for each alloy type were impacted by tungsten alloy projectiles at impact velocity of $1120 \mathrm{~m} / \mathrm{s}$. Residual depth of penetration measurements showed that the Ti-8Al-1Mo-1V alloy had lower ballistic performance than that of Ti-6Al-4V alloy. This was because of its better material properties. Comparisons were also made with $99.5 \%$ alumina ceramics for performance baselines which showed that the ballistic performance of titanium was found to be comparable to alumina at thin tile thicknesses, but the titanium performance was low compared with alumina for thicker thicknesses. However, titanium alloys had a number of important practical advantages when becoming a part of real armor systems such as: multi-hit capability; durability against impact and environmental damage, easy integration, and reduced life-cycle cost.

In the following, the analytical model proposed to describe the penetration of a highspeed projectile into a metallic bi-element target, consisting of a finite thickness metallic layer facing a semi-infinite RHA armor, is presented. The model identifies three modes of the projectile front which may occur during each phase of target penetration $[1,6]$. The proposed model can adequate to describe the penetration of a high-speed projectile into a semi-infinite target by setting the thickness of the front layer to be equal zero. Main assumptions and governing equations of associated with each target penetration and each mode of projectile front are presented. 


\section{ANALYTICAL MODEL}

In the proposed model, the projectile is considered as a cylindrical rod having initial length $L_{o}$ and initial diameter $D_{0}$ while the bi-element target consists of a front metallic layer with thickness denoted $\mathrm{H}_{\mathrm{AO}}$ backed by a semi-infinite metallic armor, Cf. Fig. 1. The different modes associated with the projectile front during each target penetration phase can be shown in Fig. 2. In the following, physical concepts, main assumptions and governing equations of the proposed model are presented. Figure 3 shows the model concept for eroding projectile and front metallic layer of the bi-element target while the backing is assumed to be stationary.

\section{Physical Concepts and Main Assumptions}

\section{Penetration into front metallic layer phase (M)}

- The penetration process through the front metallic layer is assumed to be localized.

- The eroded zone of projectile and front metallic layer ahead of projectile is assumed to have the current penetration velocity $U$, whereas the remaining of the front layer thickness and the semi-infinite metallic backing ahead of projectile are assumed to be stationary [7].

- The projectile mode may be changed during metallic layer penetration from erosion to mushrooming if the relative velocity $(\mathrm{V}-\mathrm{U})<\mathrm{V}_{\mathrm{PLAS}}$, where $V_{\text {PLAS }}\left(=0.1^{*}\left(E_{p} / \rho_{p}\right)^{1 / 2}\right)$ is the plastic wave velocity through the projectile material $[1,6]$, and/or from mushrooming to rigid if $U=\mathrm{V}$.

- The flow stress of the front layer is assumed to be constant all over the process and it is denoted by $\mathrm{Y}_{\mathrm{A}}$.

\section{Penetration into semi-infinite metallic backing phase (SI)}

- The remaining of projectile penetrates alone the semi-infinite metallic backing. The projectile mode may be changed from erosion to mushrooming and/from mushrooming to rigid during this phase.

- The surface of semi-infinite metallic backing ahead of projectile is subjected to erosion and forms a crater. The backing armor material around the crater is assumed to be stationary [7].

- The penetration process of the semi-infinite backing continues until the projectile penetration velocity vanishes, i.e. when the projectile stops inside the semiinfinite backing or when the eroded projectile is completely consumed [8].

\section{Model Structure and Basic Equations}

For each penetration stage (according to the mode of projectile front), the following system of equations has been derived:

- The equation of the penetration velocity $U$ as function of the velocity $V$.

- The time rate of change of length of projectile rigid mass $\mathrm{L}$.

- The deceleration of projectile rigid mass during its penetration into the bielement target.

- For each projectile mode, the time rate of change of projectile penetration depth $Z$ is represented by: 


$$
\frac{d Z}{d t}=U
$$

A summary for the different possibilities of phases and stages of the penetration process of a metallic layer facing a semi-infinite armor is shown in Table 1.

\section{Modeling the Projectile Modes}

\section{Projectile erosion}

At high impact velocities, the projectile front starts to erode or break up. The main equations representing the current projectile mode are [7]:

(i) The time rate of change of the length of projectile rigid mass:

$$
\frac{d L}{d t}=-(V-U)
$$

(ii) Deceleration of the projectile rigid part during penetration:

$$
\frac{d V}{d t}=-\frac{Y_{p}}{\rho_{p} L}
$$

\section{Projectile mushrooming}

The projectile decelerates during penetration. A plastic deformation at the projectile front will take place instead of erosion as shown in Fig.2. the main equations representing this mode are [1]:

(i) Time rate of change of length of projectile rigid mass:

$$
\frac{d L_{E L A S}}{d t}=-V_{P L A S}
$$

(ii) Deceleration of the projectile rigid mass during penetration:

$$
\frac{d V}{d t}=-\frac{Y_{p}}{\rho_{p} L_{E L A S}}
$$

\section{Rigid projectile}

When $\mathrm{U}=\mathrm{V}$, the projectile is assumed as a rigid mass and the remaining projectile length is $L_{E R O}$. The following equation determines the deceleration [1]:

$$
\frac{d U}{d t}=\frac{d V}{d t}=-\frac{Y_{p}}{\rho_{p} L_{E R O}} .
$$


Table 1. The different possibilities of phases and stages representing the complete penetration process of a metallic layer facing a semi-infinite armor

\begin{tabular}{|c|c|c|c|c|c|}
\hline Phase & $\begin{array}{c}\text { Stage } \\
\text { design. }\end{array}$ & $\begin{array}{c}\text { Start } \\
\text { condition }\end{array}$ & $\begin{array}{l}\text { Projectile } \\
\text { mode }\end{array}$ & $\begin{array}{c}\text { End } \\
\text { condition }\end{array}$ & Next stage \\
\hline \multirow{5}{*}{$\begin{array}{l}\text { penetration } \\
\text { into front } \\
\text { layer (M) }\end{array}$} & \multirow{2}{*}{ M-1 } & \multirow{2}{*}{$\mathrm{V}-\mathrm{U}>\mathrm{V}_{\mathrm{PLAS}}$} & \multirow{2}{*}{ erode } & $\mathrm{V}-\mathrm{U}<\mathrm{V}_{\mathrm{PLAS}}$ & M-2 \\
\hline & & & & $\mathrm{Z}=\mathrm{H}_{\mathrm{AO}}$ & Sl-1 \\
\hline & \multirow{2}{*}{ M-2 } & \multirow{2}{*}{$\mathrm{V}-\mathrm{U} \leq \mathrm{V}_{\mathrm{PLAS}}$} & \multirow{2}{*}{ mushroom } & $\mathbf{U}=\mathbf{V}$ & M-3 \\
\hline & & & & $Z=H_{A O}$ & $\mathrm{SI}-2$ \\
\hline & M-3 & $\mathrm{U}=\mathrm{V}$ & rigid & $Z=H_{A O}$ & SI-3 \\
\hline \multirow{3}{*}{$\begin{array}{l}\text { penetration } \\
\text { into semi- } \\
\text { infinite } \\
\text { backing (SI) }\end{array}$} & SI-1 & $V-U>V_{P L A S}$ & erode & $\mathrm{V}-\mathrm{U}<\mathrm{V}_{\mathrm{PLAS}}$ & $\mathrm{SI}-2$ \\
\hline & $\mathrm{SI}-2$ & $\mathrm{~V}-\mathrm{U} \leq \mathrm{V}_{\mathrm{PLAS}}$ & mushroom & $U=V$ & SI-3 \\
\hline & SI-3 & $\mathbf{U}=\mathbf{V}$ & rigid & $U=0.0$ & $\begin{array}{l}\text { End of } \\
\text { penetration } \\
\text { process }\end{array}$ \\
\hline
\end{tabular}

\section{Modeling the Penetration Stages of a Bi-Element Target}

Phase (I): penetration into front metallic layer facing a semi-infinite metallic $\operatorname{armor}(\mathrm{M})$ :

In this phase, there are three penetration stages associated with front projectile modes as mentioned in Table 1.

Stage (1): penetration of eroded projectile into front metallic layer (M-1)

In this stage, the condition $\mathrm{V}-\mathrm{U} \geq \mathrm{V}_{\mathrm{PLAS}}$ is satisfied. Both the projectile and metallic layer material at the interface are subjected to erosion. The main equations representing the current stage are:

(i) The interface force, $F[1,6]$;

$$
F=\left[\rho_{P}(V-U)^{2}+Y_{P}\right] A_{o}=Y_{A O} A_{O}+U^{2} \rho_{A} A_{o}
$$

(ii) The penetration velocity " $\mathrm{U}$ " is derived from the previous equation as function of velocity of projectile rigid mass " $\mathrm{V}$ " as:

$$
U=\frac{V-\sqrt{\mu_{A} V^{2}+\left(1-\mu_{A}\right) A_{A}}}{\left(1-\mu_{A}\right)}
$$

where

$$
\mu_{A}=\frac{\rho_{A}}{\rho_{P}}
$$


and

$$
A_{A}=\frac{Y_{A}-Y_{P}}{\rho_{P}}
$$

\section{- End conditions:}

The stage terminates if one of the following conditions is met:

a) $\mathrm{V}-\mathrm{U}<\mathrm{V}_{\mathrm{PLAS}}$; where the projectile mode changes from erosion to mushroom. The stage (M-2) follows the current penetration stage.

b) $\mathrm{Z}=\mathrm{H}_{\mathrm{AO}}$, i.e. the front metallic layer is totally eroded and the eroded projectile starts to penetrate the semi-infinite backing armor. The stage (SI-1) follows the current stage.

\section{Stage (2): penetration of mushroomed projectile into front metallic layer (M-2)}

If the condition $\mathrm{V}-\mathrm{U}<\mathrm{V}_{\mathrm{PLAS}}$ is satisfied, the projectile mode changes to be mushroom. The main equations representing the current stage are:

(i) The interface force, $F[1,6]$;

$$
F=\left[\rho_{P}\left\{V_{P L A S}(V-U)-\left(\frac{U-U_{O L D}}{d t}\right)\left(L_{E R O}-L_{E L A S}\right)\right\}+Y_{P}\right] A_{O}=Y_{A} A_{O}+U^{2} \rho_{A} A_{O}
$$

(ii) The current penetration velocity $\mathrm{U}$ as a function of $\mathrm{V}$ :

$$
U=\frac{-\left(V_{P L A S}+\frac{V_{P L A S} t_{\text {mush }}}{d t}\right)+\sqrt{\left(V_{P L A S}+\frac{V_{P L A S} t_{\text {mush }}}{d t}\right)^{2}-4 \mu_{A}\left[A_{A}-\frac{U_{O L D} V_{P L A S} t_{\text {mush }}}{d t}-V V_{P L A S}\right]}}{2 \mu_{A}}
$$

where

$$
L_{E R O}-L_{E L A S}=V_{P L A S} \cdot t_{m u s h}
$$

and

$$
t_{\text {mush }}=\left(t-t_{\text {erod }}\right)
$$

\section{- End conditions:}

This stage terminates if one of the following conditions is met:

a) When $U=V$; the projectile mode changes to be rigid, stage. The stage (M-3) follows the current stage.

b) $Z=H_{A O}$, i.e. the metallic layer is totally penetrated and the eroded projectile starts to penetrate the semi-infinite backing armor. The stage (SI-1) follows the current stage.

\section{Stage (3): penetration of rigid projectile into front metallic layer (M-3)}

- The penetration velocity $U(=V)$ is calculated using Eqn. (6).

\section{End conditions:}

a) $U=$ zero then the projectile stops and the penetration is terminated. 
b) $\mathrm{Z}=\mathrm{H}_{\mathrm{AO}}$, i.e. the metallic layer is totally penetrated and the rigid projectile starts to penetrate the semi-infinite backing armor. The stage (SI-3) follows the current stage.

Phase (II): projectile penetration into semi-infinite metallic backing armor (SI)

It starts when the front metallic layer of bi-element target is totally penetrated; the remaining projectile (with its front mode) will penetrate into the backing armor.

\section{Stage (1): penetration of eroding projectile into semi-infinite metallic backing armor (SI-1)}

The main equations representing the current stages are:

(i) The interface force, $F[1,6]$;

$$
F=\left[\rho_{P}(V-U)^{2}+Y_{P}\right] A_{o}=U^{2} \rho_{B} A_{o}+Y_{B} A_{O}
$$

(ii) The current penetration velocity $\mathrm{U}$ as a function of $\mathrm{V}$ :

$$
U=\frac{V-\sqrt{\mu_{B} V^{2}+\left(1-\mu_{B}\right) A_{B}}}{\left(1-\mu_{B}\right)}
$$

where

$$
\mu_{B}=\frac{\rho_{B}}{\rho_{P}}
$$

and

$$
A_{B}=\frac{Y_{B}-Y_{P}}{\rho_{P}}
$$

\section{- End conditions:}

The present stage terminates if one of the following conditions is met:

a) $\mathrm{V}-\mathrm{U}<\mathrm{V}_{\mathrm{PLAS}}$, then the projectile mode changes from erosion to mushroom. The stage (SI-2) follows the current stage.

b) Projectile is completely eroded and the penetration process is terminated.

Stage (2): penetration of mushroomed projectile into semi-infinite backing armor (SI-2)

The main equations representing the current stage are:

(i) The projectile/target interface force, $\mathrm{F}[1,6]$;

$$
F=\left[\rho_{P}\left\{V_{P L A S}(V-U)-\left(\frac{U-U_{O L D}}{d t}\right)\left(L_{E R O}-L_{E L A S}\right)\right\}+Y_{P}\right] A_{O}=Y_{C} A_{O}+U^{2} \rho_{B} A_{O}
$$

(ii) The current penetration velocity "U" as a function of "V": 


$$
U=\frac{-\left(V_{P L A S}+\frac{V_{P L A S} t_{\text {mush }}}{d t}\right)+\sqrt{\left(V_{P L A S}+\frac{V_{P L A S} t_{\text {mush }}}{d t}\right)^{2}-4 \mu_{B}\left[A_{B}-\frac{U_{O L D} V_{P L A S} t_{\text {mush }}}{d t}-V V_{P L A S}\right]}}{2 \mu_{B}}
$$

\section{- End conditions:}

The current stage terminates if one of the following conditions is met:

a) $U=V$, the projectile mode is changed to be rigid. The stage (SI-3) follows the current stage.

b) The projectile stops to penetrate the target; i.e. $U$ is equal to zero.

\section{Stage (3): penetration of rigid projectile into semi-infinite backing armor (SI-3)}

In this stage, the projectile penetrates the semi-infinite metallic backing armor as a rigid mass with current velocity $U$ which is equal to the current velocity $\mathrm{V}$.

\section{End conditions:}

- The projectile stops to penetrate the target; i.e. $U$ is equal to zero.

The main equations representing the different projectile modes and the penetration stages of a bi-element target are arranged and compiled into a computer program. The input data to the model are easily determined. The proposed analytical model is capable of predicting the time-histories of velocity of projectile rigid mass, penetration velocity and the depth of projectile penetration through the armor. In addition, the model can predict the total depth of penetration into the reference armor and the bielement armor, respectively, and the total time of penetration process for each armor. In the following, some of the predicted results are concerned with the determination of the ballistic efficiency of titanium frontal layer and its mass saving when replacing the steel material. The following equations used to predict the ballistic efficiency $\left(E_{m}\right)$ and mass saving (W) in percent of titanium front layer [7]:

$$
\begin{gathered}
E_{m}=\rho_{s t}\left(\frac{Z_{s t}-Z_{r e s}}{\rho_{A} H_{A o}}\right) \\
W=\left(1-\frac{\rho_{A} H_{A O}+\rho_{s t} Z_{r e s}}{\rho_{s t} Z_{s t}}\right) .100 \% .
\end{gathered}
$$

\section{RESULTS AND DISCUSSIONS}

In the following, the results of the present model are classified into: (i) model validation for both semi-infinite armor and metallic bi-element target (ii) predictions. For different impact velocities, the model predictions are concerned with the determination of ballistic efficiencies of titanium with different thicknesses, mass saving and residual penetration depth into backing semi-infinite RHA armor when each titanium thickness is used as a front layer in a bi-element target. 


\section{Model Validation}

\section{For the penetration of a semi-infinite RHA target by a DU alloy projectile}

In the proposed model, the front layer thickness is set to equal to zero. The validation of the model is done by comparing its predicted penetration depths with the corresponding measurements of $[4,5]$ at each impact velocity. The input data to the model are listed in Table 2. The projectile and the target flow stresses, $Y_{P}$ and $Y_{B}$ are represented, respectively, by [9]:

$$
Y_{p}=C_{x p} \sigma_{y p}^{D}
$$

and

$$
Y_{B}=C_{x t} \sigma_{y t}^{D}
$$

where $\mathrm{C}_{\mathrm{xp}}$ and $\sigma_{y p}^{D}$ are the flow stress multiplier and dynamic yield strength of the projectile material, respectively, $\mathrm{C}_{\mathrm{xt}}$ and $\sigma_{y t}^{D}$ are the flow stress multiplier and dynamic yield strength of target material, respectively. The dynamic yield strength of a material as function of Brinell hardness number (BHN) is determined by [10]:

$$
\sigma_{y}^{d}=3.92 * B H N[\mathrm{MPa}]
$$

Walker and Anderson [9] used a constant multiplier to determine the flow stress of target material, which gave good predicted results compared with their experimental measurements. For $\mathrm{V}_{i}>1200 \mathrm{~m} / \mathrm{s}$, Sorensen, et al. [11] deduced that the target resistance decreased gradually with increasing impact velocity in linear manner and the target resistance is determined by estimating different values of the resistance until the matching between the predicted values of penetration depths with their corresponding measurements is obtained.

In the following, the projectile strength multiplier used by Walker and Anderson is applied herein, whereas the target flow stress multiplier is modified to comply with the concept of Ref. [11] in the form of linear relation with impact velocity:

$$
C_{x t}=a+b V_{i}
$$

where $a$ and $b$ are constants. This relation is fed into the model.

Table 3 lists the multiplier equation and the predicted penetration depth and the relative difference between the model predication and the corresponding experimental measurements of Ref. [5] at each impact velocity. The maximum difference between the predicted penetration depth and the corresponding experimental measurements is found to be $7 \%$ at $V_{i}=1047 \mathrm{~m} / \mathrm{s}$. It can be seen that the trend of multiplier coefficient decrease with the increase of impact velocity which proves the deduced results of Ref. [11]. 
Table 2. Input data of projectile and bi-element targets to the model $[4,5]$.

\begin{tabular}{|c|c|c|c|c|c|}
\hline Part/ material & $\begin{array}{c}\text { Diameter } \\
{[\mathrm{mm}]}\end{array}$ & $\begin{array}{c}\text { Length } \\
{[\mathrm{mm}]}\end{array}$ & $\begin{array}{c}\text { Density } \\
{\left[\mathbf{k g} / \mathbf{m}^{3}\right]}\end{array}$ & $\begin{array}{c}\text { Hardness } \\
{[\mathrm{BHN}]}\end{array}$ & $\begin{array}{c}\text { Sonic wave } \\
\text { velocity [m/s] }\end{array}$ \\
\hline $\begin{array}{c}\text { Projectile/DU } \\
{[\mathrm{U} 3 / 4 \% \mathrm{Ti}]}\end{array}$ & 7.7 & 77 & 18600 & 373 & 2490 \\
\hline $\begin{array}{c}\text { Facing plate/ titanium } \\
{[6 \% \mathrm{Al} / 4 \% \mathrm{~V}]}\end{array}$ & Different thicknesses & 4450 & 321 & - \\
\hline $\begin{array}{c}\text { Backing armor/RHA } \\
{[\text { Mil - A-12560] }}\end{array}$ & \multicolumn{2}{|c|}{ Semi-infinite } & 7850 & 255 & - \\
\hline
\end{tabular}

Table 3. Measured depths of penetration into semi-infinite RHA [5], and the corresponding predictions of the present model.

\begin{tabular}{|c|c|c|c|c|c|}
\hline No. & $\begin{array}{l}\text { Impact } \\
\text { velocity } \\
\mathrm{V}_{\mathrm{i}},[\mathrm{m} / \mathrm{s}]\end{array}$ & $\begin{array}{l}\text { Measured } \\
\text { Depth [5], } \\
\text { [mm] }\end{array}$ & $\begin{array}{c}\text { Multiplier } \\
\text { equation } \\
\mathrm{C}_{\mathrm{xt}}\end{array}$ & $\begin{array}{c}\text { Predicted } \\
\text { depth, } Z_{\text {st }} \\
{[\mathrm{mm}]}\end{array}$ & $\begin{array}{c}\text { Absolute. } \\
\text { relative differ., } \\
\Delta Z,[\%]\end{array}$ \\
\hline 1 & 1047 & 43.2 & \multirow{8}{*}{ 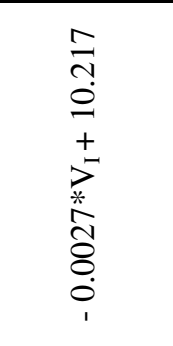 } & 40 & 7 \\
\hline 2 & 1070 & 44 & & 42.5 & 3 \\
\hline 3 & 1209 & 54 & & 56.5 & 5 \\
\hline 4 & 1264 & 61 & & 61.5 & 1 \\
\hline 5 & 1550 & 78 & & 82.3 & 6 \\
\hline 6 & 1629 & 88 & & 86.6 & 2 \\
\hline 7 & 1747 & 91 & & 92.2 & 1 \\
\hline 8 & 1897 & 101 & & 98.1 & 2.87 \\
\hline
\end{tabular}

\section{For the penetration of a titanium semi-infinite target by a DU alloy projectile}

In the proposed model, the target flow stress of titanium semi-infinite armor is determined by matching the measured penetration depth into titanium semi-infinite armor of Ref. [5] with the corresponding prediction of the present model at each impact velocity. Based on the predicted flow stress multipliers, Equation (20) is determined for the titanium semi-infinite armor and fed into the model. Table 4 lists the measured impact velocities and the corresponding penetration depths of Ref. [7]. In addition, the multiplier equation, the predicted penetration depth and the relative difference between the model predication and the corresponding experimental measurement of Ref. [5] at each impact velocity are also listed in the same table. The maximum difference between the predicted penetration depth and the corresponding experimental measurements is found to be $8.5 \%$ at $V_{i}=1111 \mathrm{~m} / \mathrm{s}$.

\section{For the penetration of a bi-element metallic target by a DU alloy projectile}

To predict the penetration depth into bi-element armor, consisting of a finite thickness of titanium front layer facing a semi-infinite $\mathrm{RHA}$, the proposed model is fed with the data listed in Table 2. The measured depths of penetration into different $\mathrm{Ti} / \mathrm{RHA}$ targets at $\mathrm{V}_{\mathrm{i}}=1500 \mathrm{~m} / \mathrm{s}$ are only available [4]. So, the coefficient expressing 
Table 4. Measured depths of penetration into semi-infinite titanium armor [5], and the corresponding predictions of the present model.

\begin{tabular}{|c|c|c|c|c|c|}
\hline No. & $\begin{array}{l}\text { Impact } \\
\text { velocity } \\
V_{i},[\mathrm{~m} / \mathrm{s}]\end{array}$ & $\begin{array}{c}\text { Measured } \\
\text { Depth [6], } \\
{[\mathrm{mm}]}\end{array}$ & $\begin{array}{c}\text { Multiplier } \\
\text { equation } \\
C_{x t}\end{array}$ & $\begin{array}{c}\text { Predicted } \\
\text { depth, } Z_{\text {st }} \\
{[\mathrm{mm}]}\end{array}$ & $\begin{array}{c}\text { Absolute. } \\
\text { relative differ. } \\
\Delta Z \text {, [\%] }\end{array}$ \\
\hline 1 & 1111 & 49.5 & \multirow{9}{*}{ 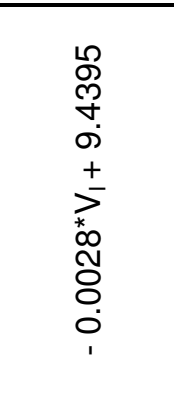 } & 45.3 & 8.5 \\
\hline 2 & 1161 & 50 & & 51.4 & 2.8 \\
\hline 3 & 1325 & 67.5 & & 70.5 & 4.4 \\
\hline 4 & 1452 & 81 & & 81.1 & 0.1 \\
\hline 5 & 1537 & 89 & & 92.1 & 3.5 \\
\hline 6 & 1627 & 105 & & 100.1 & 4.7 \\
\hline 7 & 1709 & 109 & & 106.8 & 2.0 \\
\hline 8 & 1770 & 109.6 & & 111.4 & 1.6 \\
\hline 9 & 1924 & 122.7 & & 121.8 & 0.7 \\
\hline
\end{tabular}

titanium flow stress multiplier will be taken as a constant as that used with Ref. [9]. For $V_{i}=1500 \mathrm{~m} / \mathrm{s}$, the constant multiplier is determined by matching the experimental measurement of Ref. [4] with the corresponding model prediction. Because of the lack of experimental data for the penetration of Ti/RHA targets at different impact velocities, the multiplier equation listed in Table 4 for semi-infinite titanium alloy targets is used.

Table 5 lists the measured total penetration depths into Ti/RHA armors with different titanium thicknesses at $\mathrm{V}_{i}=1500 \mathrm{~m} / \mathrm{s}$ [4]. The total penetration depth corresponding to each measurement is predicted considering a constant multiplier and the linear relation of the flow stress multiplier of titanium alloy material with impact velocity. For considering a constant multiplier, the maximum difference between the measured total penetration depth and the corresponding predicted one is found to be $3 \%$ when the frontal layer thickness of titanium is $78 \mathrm{~mm}$. When considering the liner relation of multiplier as function of impact velocity, the maximum difference between the measured total penetration depth and the corresponding predicted one is found to be $6.3 \%$ at the same frontal titanium thickness.

Based on the listed results in Table 5, the titanium flow stress multiplier in any bielement target is considered to be constant and is fed into the model with a value of 4.9 , Cf. Table 5.

\section{Predictions Due to the Penetration of DU Projectiles into Ti/RHA Targets}

Figure 4 plots the predicted residual penetration depth into semi-infinite steel armor backing titanium plate with different thicknesses at different impact velocities. It is seen form the figure that the residual penetration depth decreases with increasing the titanium thickness at each impact velocity. In addition, the slope of $Z_{\text {res }} / \mathrm{H}_{\mathrm{Ao}}$ is constant for each considered impact velocity. This means that the ratio of $Z_{\text {res }} / \mathrm{H}_{\mathrm{Ao}}$ is independent of impact velocity and titanium thickness. This result is similar to that obtained by Wickert, et al. [12]. 
Table 5. Experimental measurements of Ref. [4] of DU projectile penetration into titanium plates with different thicknesses, facing a semi-infinite RHA and the corresponding predictions of the model in case of both constant multiplier and multiplier equation for titanium material.

\begin{tabular}{|c|c|c|c|c|c|c|c|c|c|}
\hline \multirow[b]{2}{*}{ No. } & \multirow{2}{*}{$\begin{array}{c}\text { Layer } \\
\text { Thick, } \\
\mathbf{H}_{\mathrm{AO}} \\
{[\mathrm{mm}]}\end{array}$} & \multirow{2}{*}{$\begin{array}{c}\text { Nominal } \\
\text { Impact } \\
\text { Velocity, } \\
V_{i}[\mathrm{~m} / \mathrm{s}]\end{array}$} & \multirow{2}{*}{$\begin{array}{c}\text { Measured } \\
\text { total depth } \\
\text { of } \\
\text { penetration, } \\
Z_{\text {ex }}[\mathrm{mm}]\end{array}$} & \multicolumn{3}{|c|}{ Multiplier constant $C_{a}$} & \multicolumn{3}{|c|}{$\begin{array}{c}\text { Multiplier equation } \\
\mathrm{C}_{\mathrm{a}}=-0.0028^{*} \mathrm{Vi}+9.4395\end{array}$} \\
\hline & & & & Value & $\begin{array}{l}\text { Predicted } \\
\text { total depth } \\
\text { of penet., } \\
\mathrm{Z}_{\text {pred }} \text { [mm] }\end{array}$ & $\begin{array}{l}\Delta \mathbf{Z} \\
{[\%]}\end{array}$ & $\begin{array}{c}c a \\
C_{a} \text { at } \\
V_{i}= \\
1500 \\
{[\mathrm{~m} / \mathrm{s}]}\end{array}$ & $\begin{array}{l}\text { Predicted } \\
\text { total depth } \\
\text { of penet., } \\
Z_{\text {pred, }}[\mathrm{mm}]\end{array}$ & $\begin{array}{c}\Delta \mathbf{Z} \\
{[\%]}\end{array}$ \\
\hline 1 & 12.8 & \multirow{4}{*}{1500} & 84.47 & \multirow{4}{*}{4.9} & 83.2 & 1 & \multirow{4}{*}{5.2} & 80.7 & 4.5 \\
\hline 2 & 25.9 & & 85.9 & & 84.8 & 1 & & 82.28 & 4.2 \\
\hline 3 & 51.7 & & 89.7 & & 88 & 2 & & 85.26 & 4.9 \\
\hline 4 & $\begin{array}{l}78.0 \\
\end{array}$ & & 94 & & 91 & 3 & & 88.1 & 6.3 \\
\hline
\end{tabular}

Figure 5 shows the predicted change in residual penetration depth with impact velocities for different thicknesses of titanium. In addition, the predicted change of penetration depth into semi-infinite RHA (reference) with impact velocity is also plotted on the same figure. The present figure shows that the residual penetration into the backing semi-infinite RHA armor increases with impact velocity and the residual penetration decreases with increasing the thickness of titanium front layer.

Figure 6 shows the predicted change of limit titanium thickness at each impact velocity. The limit titanium thickness is defined by the thickness of titanium front layer at which no penetration occurs into the backing semi-infinite armor (i.e. $Z_{\text {res }}=0.0$ ) and is denoted by $\mathrm{H}_{\mathrm{AO}}{ }^{*}$. It is seen from the figure that the limit thickness increases with impact velocity.

Figure 7 plots the predicted change of limit ballistic efficiency with impact velocity which also shows the increase of limit efficiency with impact velocity.

Figure 8 plots the predicted change of ballistic efficiency of titanium front layer with its thickness at different impact velocities. It can be seen from the figure that the ballistic efficiency has similar trend at impact velocities of $1400 \mathrm{~m} / \mathrm{s}, 1500 \mathrm{~m} / \mathrm{s}$ and $1600 \mathrm{~m} / \mathrm{s}$, respectively. The titanium ballistic efficiency increases with increasing of its thickness until it reaches its maximum value at the limit thickness where $Z_{\text {res }}=0.0$ then, it decreases with increasing the titanium thickness. For $\mathrm{H}_{\mathrm{AO}}>\mathrm{H}_{\mathrm{AO}}{ }^{*}$, the thickness of titanium front layer is more than needed to stop the projectile and the ratio of $\left(\mathrm{Z}_{\mathrm{st}} / \mathrm{H}_{\mathrm{AO}}\right)$ decreases with increasing the titanium thickness. Therefore, the ballistic efficiency of titanium frontal layer decreases with increasing its thickness above the limit value.

Figure 9 plots the predicted change of ballistic efficiency with impact velocity for different titanium thicknesses. For $V_{i}>1400 \mathrm{~m} / \mathrm{s}$, the ballistic efficiency is generally increased with impact velocity for all considered titanium thickness. This may be attributed to the effect of strain rate of titanium at high impact velocities which increases the titanium resistance and consequently decreases the value of $\left(Z_{\text {st }}-Z_{\text {res }}\right)$. Then, it increases the ballistic efficiency with impact velocity. 
Figure 10 plots the predicted change of mass saving in percent with titanium thickness at different impact velocities. For each impact velocity, the model predicts that the mass saving in percent increases until the inflection point behind which the mass saving in percent starts to decrease. In addition, the mass saving in percent decreases with the increase of impact velocity for each titanium thickness. The model predicts that the titanium thickness less than $\mathrm{H}_{\mathrm{AO}}{ }^{*}$ may realize a mass saving of $30 \%$ compared with RHA. This percent may slightly increase with impact velocity.

Figure 11 Plots the predicted change of limit mass saving with impact velocity. The present figure shows that the limit mass saving may reach up to about $35 \%$ compared with $\mathrm{RHA}$ at $\mathrm{V}_{\mathrm{i}}=1800 \mathrm{~m} / \mathrm{s}$.

\section{CONCLUSIONS}

- The proposed analytical model has good predictive capabilities when assuming the flow stress of semi-infinite metallic baking armor is dependent on its deformation rate, decreasing with the increase of impact velocity [11] and the flow stress of titanium when used as front layer is constant.

- The slope of $Z_{\text {res }} / H_{A O}$ is independent of titanium plate thickness and impact velocity; this result is similar to that drawn from the experimental program of Wickert, et al. [12].

- Ballistic efficiency is dependent on $\left(Z_{s t}-Z_{\text {res }}\right) / H_{A O}$. In general, it increases with the increase of impact velocity especially for the limit thickness.

- For the limit titanium thickness, both the limit ballistic efficiency and limit mass saving increase with the increase of the impact velocity, respectively.

- Mass saving increases with the increase of thickness of titanium front layer until it reaches its maximum value which corresponds to the limit thickness then, it decreases because the thickness of titanium front layer is more than the required to defeat the projectile.

\section{REFERENCES}

[1] P.C. Den Reijer, "Impact on Ceramic Faced Armor", Ph.D. Thesis, Delft Technical University, Netherlands (1991).

[2] B.E. Hurles and F. H. Froe, "Lowering the Cost of Titanium", The AMPTIAC Quarterly, Vol. 6, No. 2, pp. 1-8 (2003).

[3] V. Thorn and S.J. Cimpoeru, "A Comparison of Ti-6Al-4V and Ti-8Al-1Mo-1V

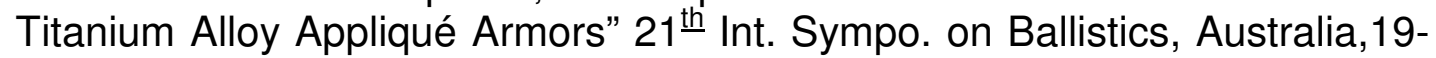
23 April (2004).

[4] N.L. Rupert and F.I. Grace, "Penetration of Semi-Infinite, Bi-Element Targets by Long Rod Penetrators", ARL-TR-666, January (1995).

[5] M.S. Burkins, J.I. Paige and J.S. Hansen, "A Ballistic Evaluation of Ti-6A14V vs. Long Rod Penetrators", ARL-TR-1146, July (1996).

[6] N. A. Fellows and P.C. Barton, "Development of Impact Model for CeramicFaced Semi-Infinite Amour", Int. J. Impact Eng., Vol. 22, pp. 793-811 (1999).

[7] H. Ali Abo El-ala, "Armor Piercing Resistance Upgrading", M.Sc. thesis, M.T.C., Egypt (2009). 
[8] A. Tate, "A Theory for the Deceleration of Long Rods", J. Mech. Phys. Solids, Vol. 15, pp. 387 - 399 (1967).

[9] J. D. Walker and C. E. Anderson Jr., "A Time Dependent Model for LongRod Penetration", Int. J. Impact Eng., Vol. 16, No. 1, pp. 19-48 (1995).

[10] R.f. Recht, "Taylor Ballistic Impact Modeling Applied to Deformation and Mass Loss Determinations", Int. Engng. Sci. Vol. 16, pp. 809-827 (1978).

[11] B. Sorensen, k. Kimsey, F. Silsby, R. Scheffler and M. Sherrick, "High Velocity Penetration of Steel Targets", Int. J. Impact Eng., Vol. 11, No. 1, pp. 107-119 (1991).

[12] M. Wickert, V. Hohler, E. Schneider and J. Faerber, "Ballistic Performance of Gamma-Ti -Al in Comparison to TI-6AL-4V", 20 $0^{\text {th }}$ Int. Sympo. on Ballistics Orlando, FL, pp. 23-27, September (2002).

Figures:

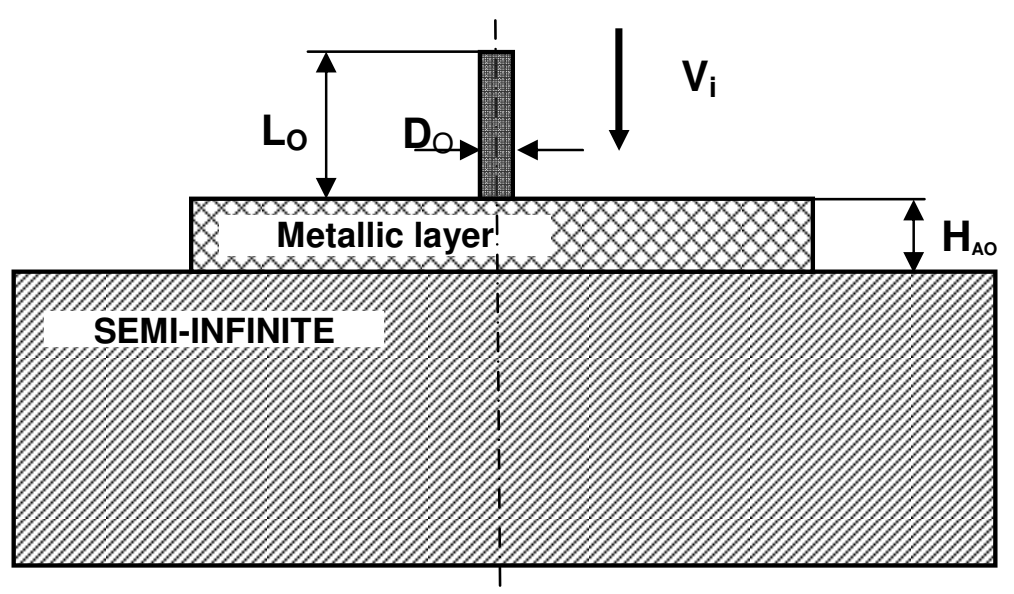

Fig.1. A schematic drawing of the metal/semi-infinite target.

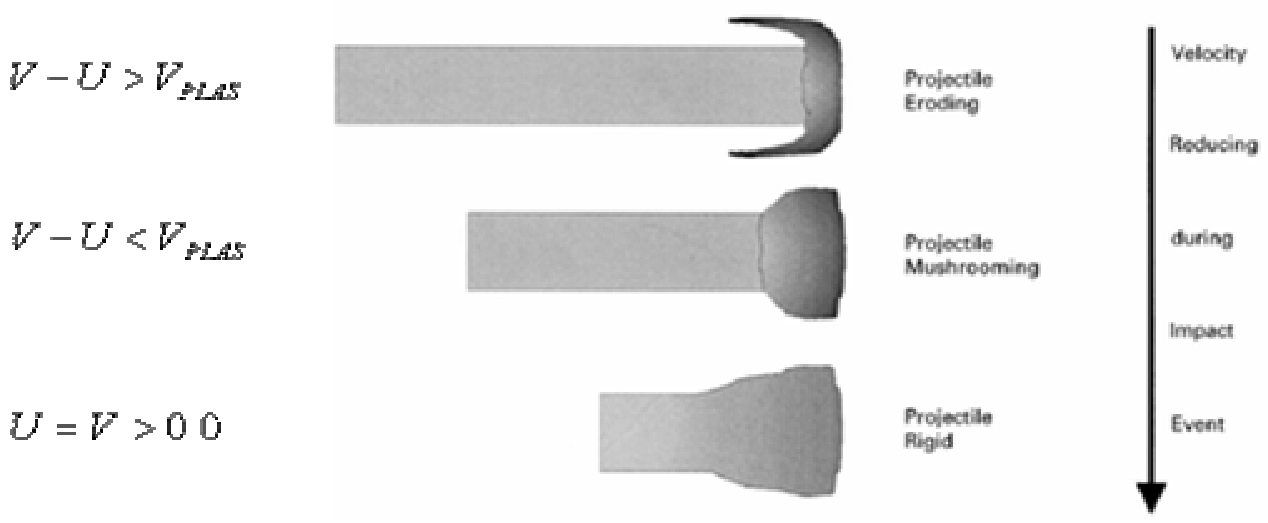

Fig. 2. Projectile behavior during penetration as its velocity falls $[1,6]$. 


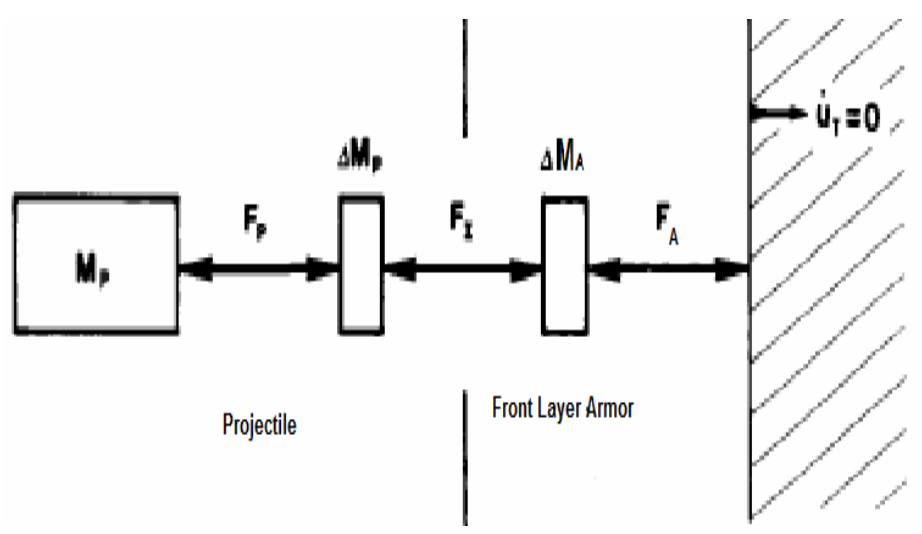

Fig. 3. Model concept for bi-element target; the backing is assumed to remain stationary while the front layer is eroded [7].

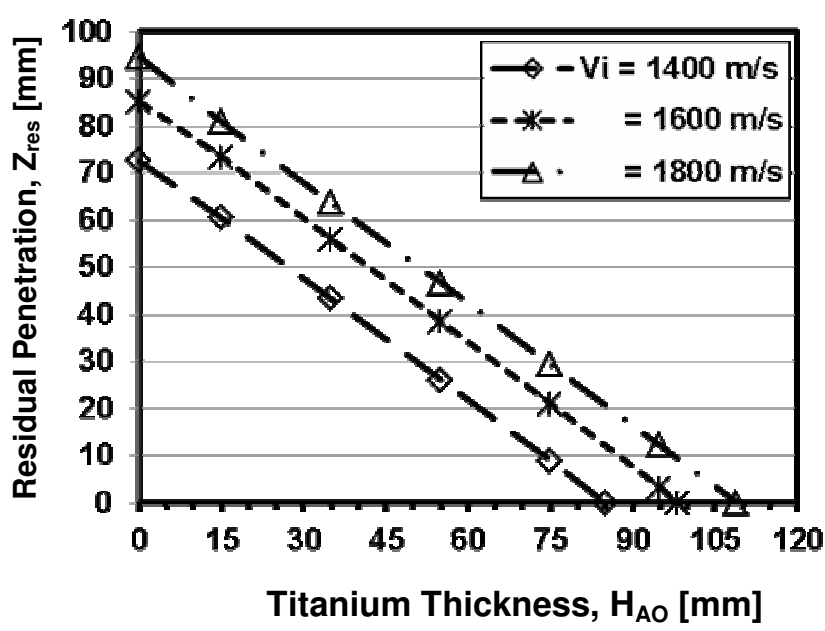

Fig. 4. Predicted change of residual penetration into semi-infinite backing RHA with titanium thickness at different impact velocities.

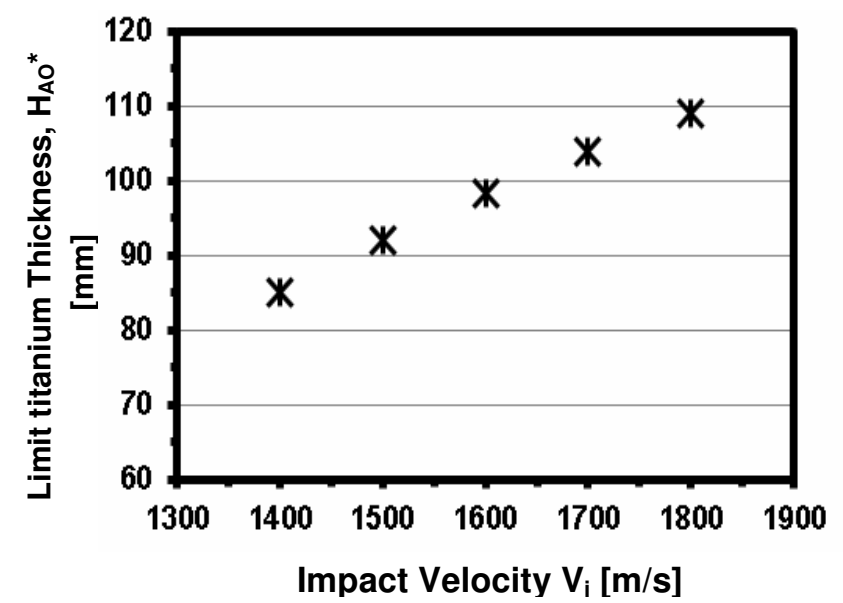

Fig. 6. Predicted change of limit titanium thickness with different impact velocity.

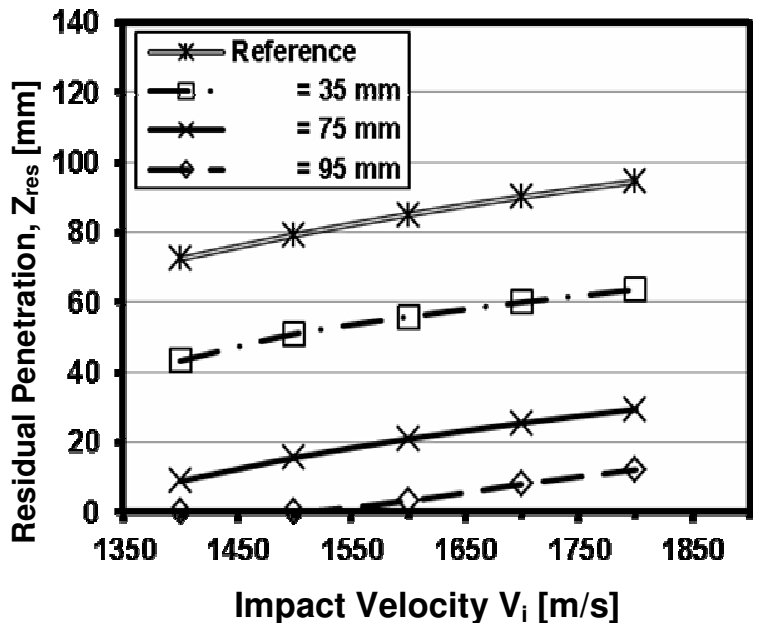

Fig. 5. Predicted change in residual penetration into semi-infinite backing RHA with impact velocity for different thicknesses of titanium.

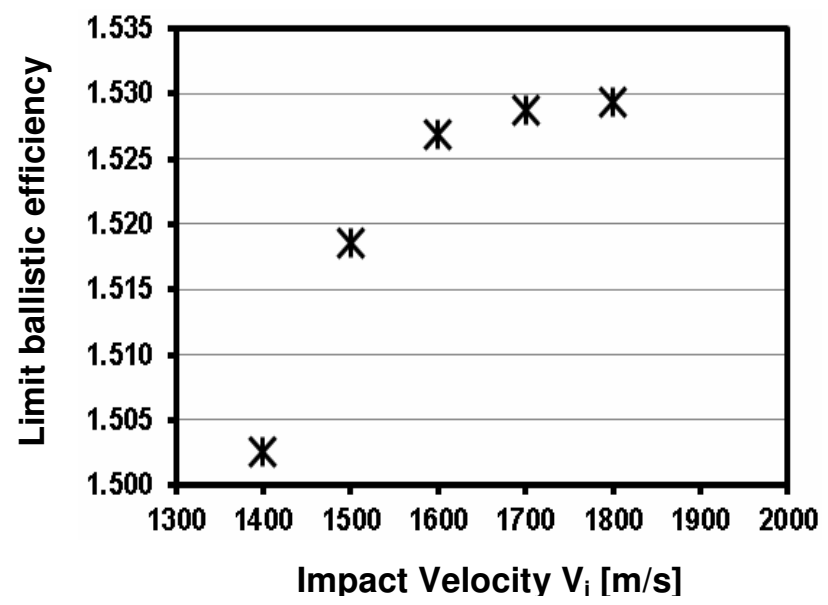

Fig. 7. Predicted change of limit ballistic efficiency with impact velocity. 


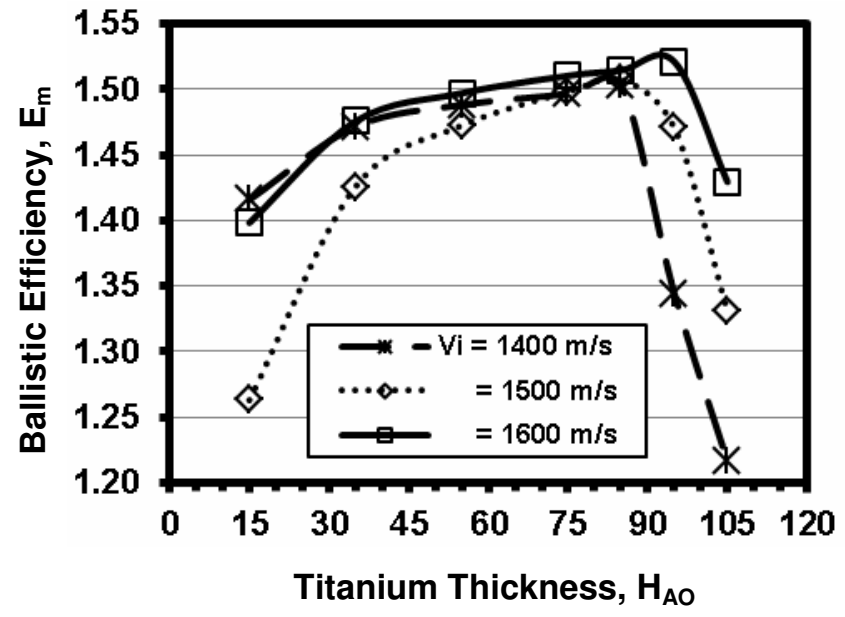

Fig. 8. Predicted change of ballistic efficiency with titanium thickness at different impact velocities.

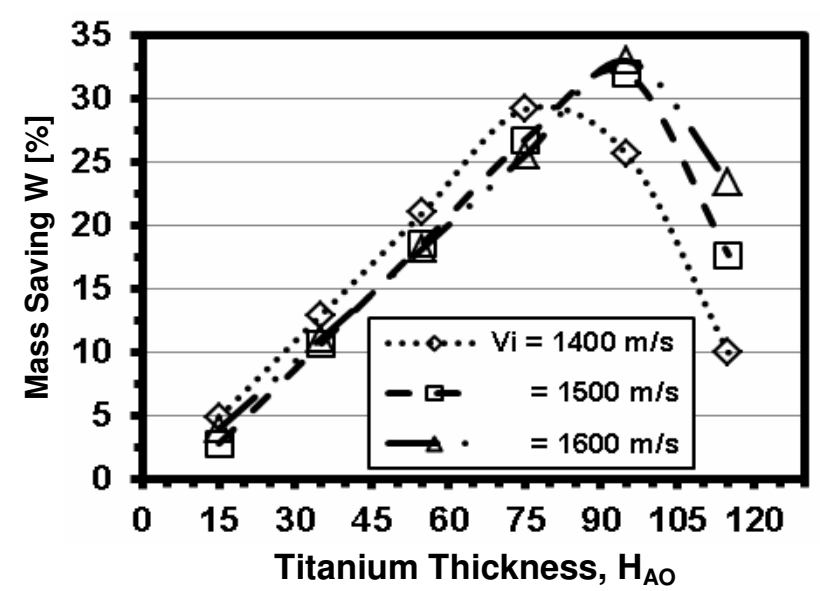

Fig. 10. Predicted change of mass saving with titanium thickness at different impact velocity.

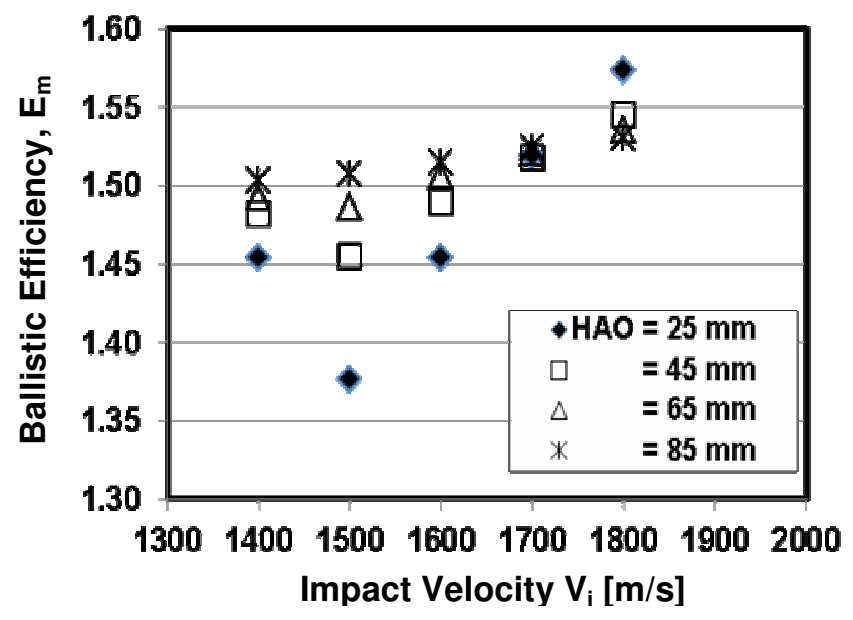

Fig. 9. Predicted change of ballistic efficiency with impact velocity for different titanium thickness.

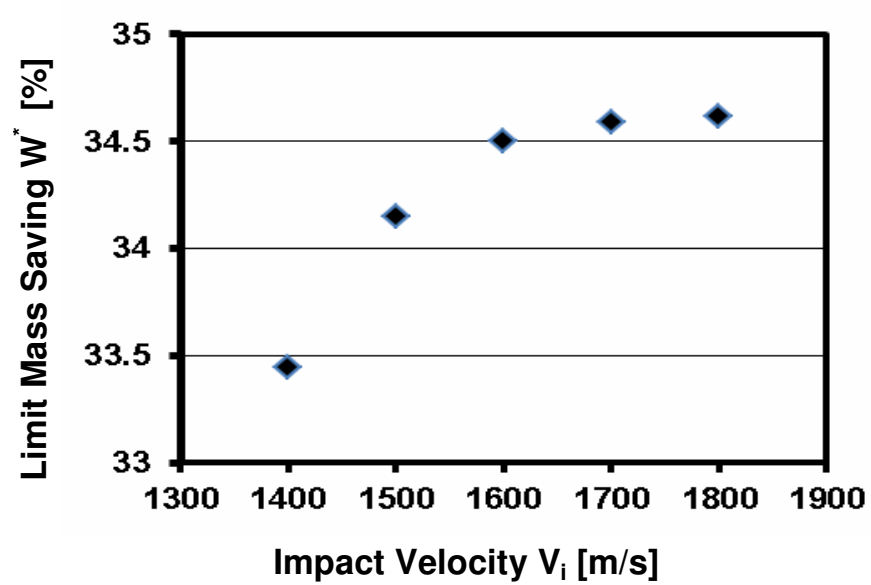

Fig. 11. Predicted change of limit mass saving with impact velocity. 